\title{
ROLE OF TILLAGE AND APPLICATION OF HERBICIDE «TRIZLAK» FOR GROWING OF WINTER WHEAT ON GRAIN QUALITY
}

\section{РОЛЬ ОБРАБОТКИ ПОЧВЫ И ПРИМЕНЕНИЯ ГЕРБИЦИДА «ТРИЗЛАК» ПРИ ВЫРАЩИВАНИИ ОЗИМОЙ ПШЕНИЦЫ НА КАЧЕСТВО ЗЕРНА}

\author{
V. Lobkov, Doctor of Agricultural Sciences \\ В.T. Лобков, доктор сельскохозяйственных наук
}

S. Plygun, N. Abakumov, Y. Bobkova, Candidates of Agricultural Sciences

С.А. Плыгун, Н.И. Абакумов, Ю.А. Бобкова, кандидаты сельскохозяйственных наук

Orel State Agrarian University, Orel City, Russia

Орловский государственный аграрный университет, г. Орёл, Россия

Phone: +7 (4862) 45-40-37, E-mail: nichogau@yandex.ru

Received April 8, 2012

\begin{abstract}
АННОТАЦИЯ
На озимой пшенице сорта Московская 39 изучалось влияние способов основной обработки почвы и гербииида Тризлак на фитосанитарное состояние посевов, урожсайность и качество зерна. В ходе исследований было установлено, что озимая пшенииа слабо реагировала на способы основной обработки почвы, влияние гербицида Тризлак статистически доказано на вариантах вспашки. При возделывании озимой пшенииы в условиях Орловской области возможен отказ от вспашки вплоть до нулевой обработки почвы, что позволяет в значительной мере снизить себестоимость зерна.
\end{abstract}

\section{ABSTRACT}

The influence of main soil treatment methods and herbicide Trizlak on the phytosanitary planting condition, productivity and grain quality was examined on the base of winter wheat Moscow 39. During study it was determined that the winter wheat under-reacted on the main soil treatment methods and the influence of the herbicide Trizlak was statistically proved on the plowing. While cultivating the winter wheat in the Orel region it's possible to avoid plowing till zero tillage, that will reduce grain costs of production to a great extent.

\section{КЛЮЧЕВЫЕ СЛОВА}

Обработка почвы; Пиеница; Гербиџиды; Очистка; Зерно; Почвообрабатывающие орудия; Методыр; Качество.

\section{KEY WORDS}

Soil treatment; Wheats; Herbicides; Purification; Grain; Tillage equipment; Methods; Quality Products; Costs.

Основная обработка почвы - это фундамент, на котором базируются все другие слагающие урожая, такие как удобрения, семена, защита растений. От срока, способа и качества основной обработки почвы зависят влагонакопление и защита её от эрозии, баланс доступных питательных веществ и биологическая активность, ко- личество и состав сорняков, вредителей и болезней, качество проведения технологических операций по возделыванию всех культур [1].

Обработке почвы принадлежит и ведущая роль в регулировании численности сорняков и предупреждении их распространения в агроценозах. В земледелии 
России только из-за засоренности посевов ежегодно теряется около $17 \%$ урожая зерна. Засоренность посевов зачастую превышает экономические пороги вредоносности, что приводит к недобору урожая, ухудшению качества продукции и дополнительным издержкам. Большая засоренность сельскохозяйственных угодий не дает возможности обеспечить высокую культуру земледелия на полях. Несмотря на научно-технический прогресс в сельском хозяйстве, острота борьбы с сорняками не ослабляется. В условиях современного земледелия ведущее место в борьбе с сорняками остается пока за агротехническими методами, как более дешевыми [2].

По данным многочисленных исследований вспашка уменьшает засоренность малолетними и многолетними сорняками на 50-60\%. Однако ей присущ ряд недостатков, главным из которых является высокая энергоемкость. Использование современной техники открыли новые возможности для поиска путей минимализации обработки почвы, разработки почвозащитных и энергосберегающих технологий $[3,4]$.

Поэтому изучение влияния различных систем основной обработки почвы в зернотравяном звене севооборота на засоренность и урожайность озимой пшеницы является особенно актуальным.

Материал и методика исследований. Исследования проводились в 2009-2011 гг. на опытном поле кафедры земледелия ФГБОУ ВПО Орел ГАУ в условиях полевого стационарного опыта в пятипольном севообороте со следующим набором культур: однолетние травы - озимая пшеница кукуруза на силос - гречиха - ячмень. Чередование культур осуществлялось во времени.

В качестве объекта исследований использовался рекомендованный для возделывания в Орловской области сорт озимой пшеницы Московская 39.

Почва опытного поля представляет собой типичную для области тёмно-серую лесную среднесуглинистую глееватую почву, почвообразующие и подстилающие породы-оглееные покровные суглинки, пятна оглеения встречаются с 75 см. Микрорельеф участка выровненный. Пахотный слой имеет слабокислую реакцию почвенного раствора (pH 5,6), достаточно высокое содержание гумуса $(4,76 \%)$ для этого типа почв и среднее содержание подвижного фосфора и обменного калия.

Схема опыта:

Фактор А (5 градаций) - обработка почвы: нулевая, плоскорез, 20-22 см, комбинированная KOS, 14-16 см, вспашка обычным плугом ПЛН- 3-35, 20-22 см, вспашка оборотным плугом Lemken, 20-22 CM.

Фактор В (2 градации) - химическая защита растений: 0 - без пестицидов; 1 - с пестицидами.

Норма высева озимой пшеницы 2,0 ц/га. Рядовой посев озимой пшеницы проводили сеялкой культиваторного типа John Deere 730. Опрыскивания гербицидом Тризлак проводилось в фазу кущения озимой пшеницы, расход рабочей жидкости составил 200 л/га.

Двухфакторный опыт размещен методом рендомизированных повторений в трёхкратной повторности. Размер делянки: длина - 30 м, ширина - 20 м, учетная площадь -120 м2 Все наблюдения, анализы и учёт проводили по общепринятым методикам.

В целом период вегетации озимой пшеницы с сентября 2010 года по июль 2011 года можно охарактеризовать как благоприятный, с повышенной температурой и небольшим дефицитом осадков, что практически не отразилось на величине урожая этой ценной культуры.

Результаты и их обсуждение. Опыты показали, что постоянные безотвальные и особенно «нулевая» обработки по сравнению со вспашкой способствуют увеличению засоренности посевов озимой пшеницы в севооборотах лесостепной зоны. В среднем за ротацию севооборотов сорняков по количеству и массе было больше на безотвальной обработке на $25 \%$, а «нулевой» - на $37 \%$ по сравнению со вспашкой.

Данные, характеризующие количество сорняков до опрыскивания гербицидом Тризлак и перед уборкой озимой пшеницы, приведены в табл. 1. 
Таблица 1 - Количество сорняков и их воздушно-сухая масса перед применением гербицида и перед уборкой озимой пшеницы

\begin{tabular}{|c|c|c|c|c|c|}
\hline \multirow[b]{2}{*}{ Вид обработки почвы } & \multirow[b]{2}{*}{ Гербицид } & \multicolumn{2}{|c|}{ до обработки } & \multicolumn{2}{|c|}{ перед уборкой } \\
\hline & & $\begin{array}{c}\text { количество, } \\
\text { шт./м }\end{array}$ & $\begin{array}{c}\text { масса воздушно- } \\
\text { сухая, г/м² }\end{array}$ & $\begin{array}{c}\text { количество, } \\
\text { шт./M }\end{array}$ & $\begin{array}{l}\text { мacca cy- } \\
\text { хая, } \Gamma / \mathrm{M}^{2}\end{array}$ \\
\hline \multirow{2}{*}{ Без обработки } & 0 & \multirow{2}{*}{90} & \multirow{2}{*}{7,6} & 112 & 37,2 \\
\hline & 1 & & & 34 & 7,4 \\
\hline \multirow{2}{*}{ Плоскорез } & 0 & \multirow{2}{*}{94} & \multirow{2}{*}{10,5} & 164 & 23,8 \\
\hline & 1 & & & 196 & 19,6 \\
\hline \multirow{2}{*}{ KOS } & 0 & \multirow{2}{*}{128} & \multirow{2}{*}{13,3} & 94 & 13,2 \\
\hline & 1 & & & 62 & 18,9 \\
\hline \multirow{2}{*}{ Плуг обычный } & 0 & \multirow{2}{*}{84} & \multirow{2}{*}{5,0} & 122 & 22,3 \\
\hline & 1 & & & 64 & 5,6 \\
\hline \multirow{2}{*}{ Плуг оборотный } & 0 & \multirow{2}{*}{162} & \multirow{2}{*}{17,7} & 88 & 20,1 \\
\hline & 1 & & & 176 & 30,5 \\
\hline \multicolumn{2}{|c|}{$\mathrm{HCP}_{05}$ для оценки существенности частных различий } & 7,91 & 0,89 & 9,64 & 3,04 \\
\hline
\end{tabular}

Как видно из приведенных данных, изначально количество сорняков по вариантам опыта существенно различалось. Наибольшая засоренность отмечалась на варианте с применением оборотного плуга (162 шт./M²), а наименьшая - с применением обычного плуга $\left(84\right.$ шт./ $\left.\mathrm{M}^{2}\right)$. Это особенно заметно, если принять во внимание не только количество сорняков, но и их воздушно сухую массу. На вариантах с применением нулевой и плоскорезной обработки изначальная засоренность так же была невысокой. Средняя степень засоренности посевов наблюдалась на варианте с применением комплексного агрегата обработки почвы. После применения гербицида, перед уборкой озимой пшеницы было проведено очередное обследование посевов на засоренность.

На варианте вспашки (LEMKEN) гербицидная обработка вдвое снизила количество сорняков, лишь незначительно увеличив их массу. Но необработанный вариант немного увеличил численность сорняков, зато их масса возросла почти в два раза.

При вспашке плугом ПЛН-3-35 к моменту уборки количество сорняков на обработанном участке возросло и составило 122 ш/м ${ }^{2}$ с увеличением массы сорняков почти в пять раз. На необработанном участке количество сорняков снизилось, практически не увеличив свою массу.

При обработке почвы агрегатом KOS обработка гербицидом слегка снизила количество сорняков, оставив их массу практически на том же уровне. На необработанном участке снижение количества сор- няков было более заметно (в два раза), однако их масса увеличилась.

Применение плоскореза и на обработанном и на необработанном гербицидом участках вызвало увеличение количества сорняков практически вдвое. Так же увеличилась и масса сорняков, причем на обработанном участке увеличение было гораздо заметнее.

При нулевой обработке почвы к моменту уборки на обработанном участке увеличилось количество сорняков, а их масса повысилась практически в пять раз. На необработанном участке количество сорняков снизилось в три раза, оставив без изменения их массу.

В современных условиях дальнейшее увеличение урожайности озимой пшеницы, улучшение его физико-химических и технологических качеств тесно связано с разработкой высокоэффективных зональных приемов возделывания: подбор оптимальных сортов культуры, способов обработки почвы, применением органических и минеральных удобрений и средств защиты растений, которые направлены на получение биологически полноценной и экологически безопасной продукции с наибольшей экономической эффективностью выращивания.

Уборка проводилась в фазу восковой спелости пшеницы методом сплошного комбайнирования. Применялся специальный комбайн для опытных участков Terrion Sampo, учетная площадь делянки составила $80 \mathrm{~m}^{2}$. Результаты полевых опытов показали, что на урожайность озимой пшеницы оказали влияние все изучаемые факторы (табл. 2). 
Как видно из данных таблицы 2, урожайность озимой пшеницы в значительной мере изменялась по вариантам опыта.

Наибольшая урожайность получена в варианте отвальной обработки почвы оборотным плугом с применением гербицида. Так же применение гербицида способствовало повышению урожайности на варианте с применением плоскорезной обработки. Не обнаружено разницы при применении гербицида в вариантах нулевой, комбинированной и отвальной (ПЛН-3-35) обработок почвы.

Таблица 2 - Урожайность озимойпшеницы в зависимости от вариантов опыта

\begin{tabular}{|c|c|c|}
\hline $\begin{array}{c}\text { Вид обработки } \\
\text { почвы }\end{array}$ & Гербицид & $\begin{array}{c}\text { Среднее по } \\
\text { варианту, ц/га }\end{array}$ \\
\hline \multirow{2}{*}{ Без обработки } & 0 & 32,90 \\
\hline & 1 & 31,30 \\
\hline \multirow{2}{*}{ Плоскорез } & 0 & 32,50 \\
\hline & 1 & 45,00 \\
\hline \multirow{2}{*}{ KOC } & 0 & 45,40 \\
\hline & 1 & 47,20 \\
\hline \multirow{2}{*}{ Плуг обычный } & 0 & 43,30 \\
\hline & 1 & 45,40 \\
\hline \multirow{2}{*}{ Плуг оборотный } & 0 & 39,00 \\
\hline & 1 & 51,70 \\
\hline \multicolumn{2}{|c|}{$\begin{array}{l}\mathrm{HCP}_{05} \text { для оценки существенности } \\
\text { частных различий }\end{array}$} & 3,07 \\
\hline
\end{tabular}

Если рассматривать урожайность безгербицидных делянок, то заметен эффект увеличения урожайности при усилении интенсивности обработки почвы. Плоскорезная обработка не имела преимуществ перед нулевой, а обработка почвы комбинированным агрегатом (KOS) оказалась значительно выгоднее обычного и особенно оборотного плугов.

Общеизвестно, что величина урожая сельскохозяйственных культур обусловлена взаимодействием ряда факторов, которые условно можно разделить на две группы - метеорологические и технологические. Ясно, что всю сложность и многогранность жизненного цикла растений на протяжении вегетационного периода может отобразить только совокупность факторов. Поэтому для видения реального значения составляющих урожая нужно учитывать даже наименее значимые показатели структуры урожая. Детальный анализ составных частей продуктивности необходим для морфологического контроля за растениями и возможности целенаправленного влияния на формирование определенных элементов структуры урожая [5].

Таблица 3 - Влияние способов основной обработки почвы на элементы структуры урожая

\begin{tabular}{|c|c|c|c|c|c|}
\hline Вид обработки почвы & 远。責 & $\begin{array}{c}\text { Количество продуктив- } \\
\text { ных колосьев, шт./м² }\end{array}$ & $\begin{array}{c}\text { Количество зёрен } \\
\text { в колосе, шт. }\end{array}$ & $\begin{array}{c}\text { Масса зерна с } \\
\text { одного колоса, } \\
\Gamma\end{array}$ & $\begin{array}{c}\text { Macca } \\
1000 \text { ce- } \\
\text { M9н, Г }\end{array}$ \\
\hline \multirow{2}{*}{ Без обработки } & 0 & 258 & 34 & 1,28 & 37,5 \\
\hline & 1 & 244 & 34 & 1,28 & 37,2 \\
\hline \multirow{2}{*}{ Плоскорез } & 0 & 254 & 34 & 1,28 & 37,6 \\
\hline & 1 & 341 & 35 & 1,32 & 37,7 \\
\hline \multirow{2}{*}{ КOC } & 0 & 369 & 32 & 1,23 & 38,4 \\
\hline & 1 & 408 & 31 & 1,16 & 37,5 \\
\hline \multirow{2}{*}{ Плуг обычный } & 0 & 281 & 37 & 1,54 & 41,6 \\
\hline & 1 & 320 & 35 & 1,42 & 40,2 \\
\hline \multirow{2}{*}{ Плуг оборотный } & 0 & 393 & 29 & 0,99 & 33,8 \\
\hline & 1 & 491 & 30 & 1,05 & 35,3 \\
\hline \multicolumn{2}{|c|}{$\begin{array}{l}\mathrm{HCP}_{05} \text { для оценки существен- } \\
\text { ности частных различий }\end{array}$} & 24,79 & 2,29 & 0,092 & 2,60 \\
\hline
\end{tabular}

Bce показатели, определяющие массу зерна колоса, зависят от особенностей сорта, метеорологических условий и могут регулироваться большинством агротехнических мероприятий. Как видно из данных табл. 3, изменения в структуре урожая по вариантам опыта были существенны.
На первом (нулевая обработка, оба фона по гербициду) и втором (плоскорезная обработка без гербицида) отсутствовали различия между изучаемыми показателями структуры урожая. В дальнейшем на этих делянках была получена практически одинаковая урожайность. Увеличение числа продуктивных стеблей на варианте 
плоскорез+гербицида привело к значительному увеличению урожайности практически без изменения количества зерен в колосе, массы зерна с одного колоса и массы 1000 зерен.

На варианте применения комбинированного агрегата для обработки почвы проявилась достоверная разница по показателям структуры урожая озимой пшеницы. На фоне безгербицидной обработки уменьшилось количество продуктивных стеблей, но увеличились озерненность и масса зерна с одного колоса. Различия в массе 1000 семян статистически недостоверны. Та же закономерность прослеживается и на вариантах с применением отвальной обработки почвы.

Ценность продуктов, вырабатываемых из пшеницы, в том числе и макароннокрупяных изделий, зависит от качества её зерна, важными биохимическими показателями которого являются содержание клейковины и белка [6].

Некоторые химические показатели качества зерна приведены в табл. 4.

Таблица 4 - Химические показатели качества зерна

\begin{tabular}{|c|c|c|c|c|}
\hline Вид обработка почвы & Гербицид & $\begin{array}{l}\text { Содержание } \\
\text { протеина, \% }\end{array}$ & $\begin{array}{l}\text { Содержание } \\
\text { крахмала, \% }\end{array}$ & $\begin{array}{c}\text { Содержание сырой } \\
\text { клейковины, }\end{array}$ \\
\hline \multirow{2}{*}{ Без обработки } & 0 & 15,73 & 64,17 & 27,90 \\
\hline & 1 & 14,30 & 65,50 & 23,67 \\
\hline \multirow{2}{*}{ Плоскорез } & 0 & 14,40 & 65,37 & 24,50 \\
\hline & 1 & 16,40 & 63,67 & 29,83 \\
\hline \multirow{2}{*}{ KOC } & 0 & 15,43 & 64,73 & 28,00 \\
\hline & 1 & 15,03 & 64,93 & 26,87 \\
\hline \multirow{2}{*}{ Плуг обычный } & 0 & 14,47 & 65,43 & 25,50 \\
\hline & 1 & 14,10 & 65,60 & 24,30 \\
\hline \multirow{2}{*}{ Плуг оборотный } & 0 & 15,63 & 64,20 & 28,00 \\
\hline & 1 & 15,47 & 64,17 & 27,80 \\
\hline \multicolumn{2}{|c|}{$\begin{array}{c}\mathrm{HCP}_{05} \text { для оценки существенности } \\
\text { частных различий }\end{array}$} & 1,00 & 4,44 & 1,74 \\
\hline
\end{tabular}

Как видно из данных таблицы 4, различные элементы технологии возделывания озимой пшеницы оказали влияние на содержание белка и клейковины, практически не изменив содержание крахмала в зерне.

Применение гербицида снизило содержание белка на варианте нулевой обработки почвы и повысило в варианте с плоскорезной обработкой. В других вариантах влияние гербицида не отмечено, здесь проявилось действие приемов обработки почвы. Применение нулевой обработки, КОСа и оборотного плуга увеличил содержание белка свыше 15\%, на вариантах плоскореза и обычного плуга содержание белка в зерне колебалось в пределах 14,10-14,47\%.

Содержание сырой клейковины на всех вариантах, кроме плоскорезной обработки, уменьшалось при применении гербицида. 27,9\% отмечалось на варианте нулевой обработки почвы, почти такое же (28\%) было в вариантах с отвальной вспашкой оборотным плугом и комбинированной обработкой. Экономические показатели производ- ства зерна по вариантам опыта довольно сильно различались (табл.5).

Себестоимость одного центнера продукции на всех вариантах, кроме вариантов 3-0, 3-1 и 5-1, превышала 200 рублей, а в варианте 0-1 составила 306,64 руб/ц. Это объясняется невысоким уровнем урожайности (от 32,9 ц/ до 39,0 ц/га) на этих вариантах. На вариантах с нулевой обработкой почвы и на плоскорезной обработке без применения гербицида чистый доход и рентабельность производства были примерно одинаковыми и довольно низкими. На трех последних варианта, в связи с существенным увеличением урожайности и небольшим ростом производственных затрат снизилась себестоимость продукции и, соответственно, выросли значения чистого дохода и рентабельности производства. 
Таблица 5 - Экономические показатели возделывания озимой пшеницы по вариантам опыта

\begin{tabular}{|c|c|c|c|c|c|}
\hline \multirow[b]{2}{*}{$\begin{array}{l}\text { Вариант об- } \\
\text { работки поч- } \\
\text { вы }\end{array}$} & \multirow[b]{2}{*}{ Гербицид } & \multicolumn{2}{|c|}{ Урожайность } & \multirow[b]{2}{*}{$\begin{array}{c}\text { Себестоимость } 1 \text { ц } \\
\text { основной продукции, } \\
\text { руб. }\end{array}$} & \multirow[b]{2}{*}{$\begin{array}{l}\text { Рентабельность } \\
\text { (убыточность), \% }\end{array}$} \\
\hline & & $\begin{array}{l}\text { основной про- } \\
\text { дукции, ц/га }\end{array}$ & $\begin{array}{c}\text { побочной } \\
\text { продукции, } \\
\text { ц/га }\end{array}$ & & \\
\hline \multirow{2}{*}{ Без обработки } & 0 & 32,9 & 2,9 & 285,8 & 41,5 \\
\hline & 1 & 31,3 & 2,7 & 306,6 & 31,9 \\
\hline \multirow{2}{*}{ Плоскорез } & 0 & 32,5 & 2,9 & 297,7 & 35,9 \\
\hline & 1 & 45,0 & 4,0 & 224,2 & 80,4 \\
\hline \multirow{2}{*}{ KOS } & 0 & 45,4 & 4,1 & 195,8 & 92,4 \\
\hline & 1 & 47,2 & 3,7 & 198,3 & 96,8 \\
\hline \multirow{2}{*}{$\begin{array}{c}\text { Плуг обыч- } \\
\text { ный }\end{array}$} & 0 & 43,3 & 4,2 & 209,9 & 83,6 \\
\hline & 1 & 45,4 & 4,3 & 201,7 & 85,4 \\
\hline \multirow{2}{*}{$\begin{array}{l}\text { Плуг оборот- } \\
\text { ный }\end{array}$} & 0 & 39,0 & 3,4 & 250,2 & 61,6 \\
\hline & 1 & 51,7 & 4,5 & 197,0 & 105,3 \\
\hline
\end{tabular}

Заключение. Результаты изучения влияния различных способов основной обработки почвы и средств химизации на фитосанитарное состояние посевов и урожайность и качество зерна озимой пшеницы продемонстрировали, что различные приемы обработки почвы оказывали существенное влияния на урожайность озимой пшеницы по вариантам опыта. Влияние гербицида Тризлак статистически доказано на вариантах вспашки и плоскорезной обработки. Применение плоскореза и оборотного плуга предполагает однозначное применение гербицида для защиты растений озимой пшеницы, использование комбинированного агрегата или обычного плуга уменьшает негативное влияние сорняков.
Применение гербицида Тризлак приводило к снижению содержания в зерне озимой пшеницы белка и клейковины, не влияя на содержание крахмала.

Использование техники зарубежного производства при невысоком уровне урожайности возделываемой культуры приводит к ухудшению экономических показателей технологии возделывания. Для оправдания применения дорогостоящей энергонасыщенной техники уровень урожайности озимой пшеницы должен составлять не менее 45-50 ц/га.

Экономически наиболее выгодными оказались варианты с использованием комбинированной и отвальной (оборотный плуг) обработок с использованием гербицида Тризлак.

\section{БИБЛИОГРАФИЯ}

Кадыров, С.В. Технологии программированных урожаев в ЦЧР: справочник / С.В. Кадыров, В.А. Федотов. Воронеж. 2005. - c. 200.

Орлов А. Н. Засоренность и урожайность яровой пшеницы в зависимости от элементов технологии возделывания [Текст] / А. Н. Орлов, О. А. Ткачук, Е. В. Павликова // Молодой ученый. - 2012. - №2. - С. 362-365.

Захаров, Н.Г. Влияние основной обработки почвы на засоренность посевов яровой пшеницы / Н.Г. Захаров, М.А. Полняков // Современные системы земледелия: опыт, проблемы, перспективы: материалы междуна- родной научно-практической конференции, посвященной 80-летию со дня рождения профессора Морозова В.И. - Ульяновск: Ульяновская ГCXА, 2011. - С. 98-102.

Кащеев, А.Н. Севообороты и обработка почвы в интенсивном земледелии / А.Н. Кащеев, А.Н. Орлов. - Пенза: РИО ПГСХА, 2007. - 153 с.

Грабовец А.И., Фоменко М.А. Озимая пшеница. Монография. - Ростов-наДону. ООО «Издательство Юг», 2007. - 600c.

Созинов А.А. Урожай и качество зерна / А.А. Созинов. - М.: Знание, 1976. $64 \mathrm{c}$. 